\title{
POLAROGRAPHY OF BIOLOGICAL PURINES AND PYRIMIDINES
}

\author{
Philip J. Elving \\ The University of Michigan \\ Ann Arbor, Mich.
}

\section{INTRODUCTION}

Since electron-transfer reactions are so important in biological systems, information which can be obtained in respect to the energy levels (electrical potentials) and reaction pathways involved should be helpful in the understanding, control and utilization of such reactions. Polarographically determinded half-wave potentials $\left(E_{1 / 2}\right)$ and electrode reaction paths or mechanisms readily provide such data under conditions generally similar to those encountered in biological systems, e.g., electrolytic reductions and oxidations often occur under conditions resembling those of enzymatic transformations: electron-transfer at a heterogeneous interface, previous occurrence of adsorption and/or adduct formation, dilute aqueous solution, $\mathrm{pH}$ between 2 and 9, and moderate temperature.

Postulation of the extent of correlation that may exist between electrolytic and biological redox processes must at present be largely speculation. Nevertheless, to the extent that the two kinds of processes occur under similar conditions, information obtained from the examination by electrochemical techniques of the redox behavior of compounds of biological interest may help to clarify and explain biological processes with respect to the nature of the factors, such as $\mathrm{pH}$, controlling the electron-transfer process.

The value of electrical measurement in elucidating redox behavior of biologically important organic compounds has long been recognized. However, due to the fact that few organic redox systems behave reversibly, valid potentiometric data have been obtained for only a limited number of compounds. Where such data have been systematically gathered and analyzed, the results have been fruitful, e.g., the work of Michaelis, Clark and their collaborators during the 1920's and 1930's. Since then, most studies of the redox behavior of organic compounds have been based on polarography, generally at the dropping mercury electrode (D.M.E.). Frequently, $E_{1 / 2}$ data on organic compounds so determined are the only energetic data readily obtainable by electrochemical measurement.

The present paper summarizes the results of polarographic examination of purines and pyrimidines in aqueous solution with emphasis on (a) the reaction path involved in electrochemical reduction and oxidation, (b) the effect of substituents and structure in altering the ease of reduction and the reaction path, and (c) the correlation of $\mathrm{E}_{1 / 2}$ data with electronic and other indices. The stress on reduction is simply due to the fact that, until relatively recently, systematic study of the electrochemical behavior of organic compounds was largely restricted to their reduction at mercury electrodes due to the lack of an electrode suitable for studying oxidation.

In addition to classical direct-current constant-potential polarography at the D.M.E., derived techniques-controlled electrode potential electrolysis and coulometry, cyclic voltammetry, chronopotentiometry and alternating current polarography at mercury and graphite electrodes-have been used to obtain the data to be discussed.

The polarography of purines and pyrimidines was reviewed several years 
ago $^{1}$; the present discussion largely assumes the availability of this review. Data for the polarographic reduction of selected pyrimidines and purines and for the oxidation of purines are summarized in TABLES 1 and 2.

\section{General Reaction Path}

Elving and Pullman ${ }^{2}$ proposed a general mechanistic pattern for organic electrode processes, based on the fact that the fundamental process in an organic electrochemical reduction is bond rupture, which requires only one electron to produce a free radical species; addition of a second electron completes rupture of the bond to give a carbanion. The pattern (FIGURE 1) assumes a generalized reaction site, $R: X$, where $R$ represents the reactive carbon center in the molecule and $X$ represents another carbon, oxygen, nitrogen, halogen or other atom; there may be more than one bond between $\mathrm{R}$ and $\mathrm{X}$, for example, in a $\mathrm{C}=\mathrm{N}$ linkage.

In the primary step of the electrode process, the reaction site accepts a single electron to form the electrode-activated complex, which can either revert to the original species or dissociate to give a free radical precursor and an anionic species; the latter, if a multiple bond was originally present between $\mathbf{R}$ and $\mathrm{X}$, could form a single, free radical anion. The exact nature of these species will be modified by the extent of the participation of protons, solvent molecules and other solution constituents or even the electrode surface (such participation in subsequent steps is not explicitly indicated but may be involved).

The free radical precursor can either accept a second electron immediately on formation and be reduced to the equivalent of a carbanion, or can exist as a stable, free radical species, which may then either dimerize or, at more negative potential, be further reduced to a carbanion. The charge on the carbanion, formed by either path, is neutralized either by acceptance of a

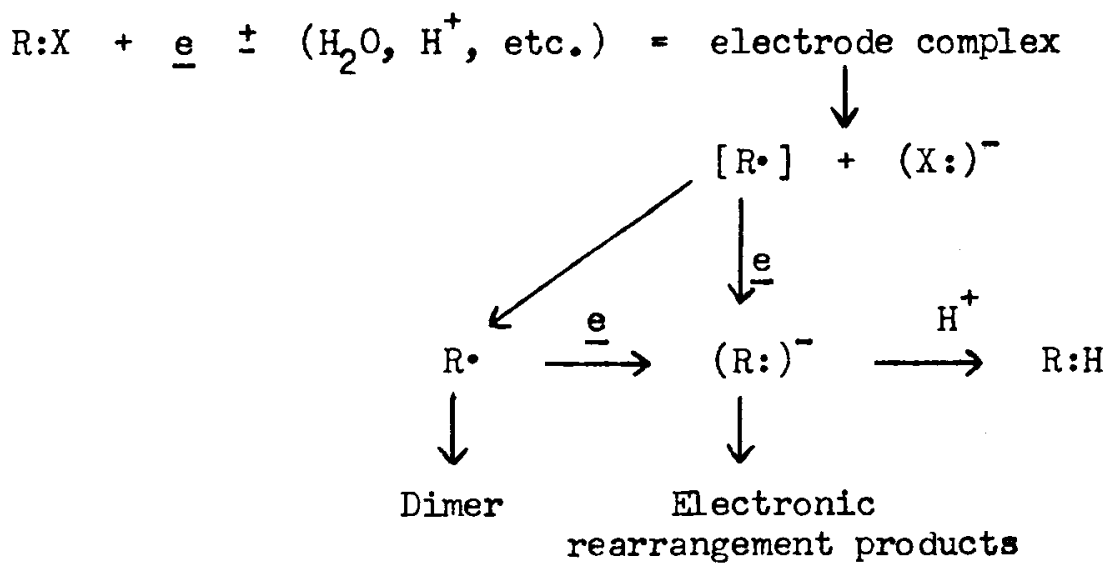

FIGURE 1. Generalized mechanistic path for an organic electrode reaction, in which $R: X$ represents the reaction site; the individual steps are discussed in the text. Allowance may have to be made for (a) the participation in the various steps of protons, solvent, other solution constituents and the electrode surface, (b) the occurrence of chemical reactions preceding, accompanying and following charge-transfer, and (c) resulting modification of the species shown. 
TABLE 1

Polarographic Reduction of Selected Pyrimidines and Purines at the Dropping Mercury Electrode ${ }^{\mathrm{a}}$

\begin{tabular}{|c|c|c|c|}
\hline Compound & $\mathrm{pH}$ & $\begin{array}{c}\mathrm{E}_{1 / 2^{\mathrm{b}}} \\
\mathrm{v} .\end{array}$ & $\mathbf{I}^{\mathbf{c}}$ \\
\hline Pyrimidine & $\begin{array}{l}0.5-5 \\
3-5 \\
5-8 \\
7-8 \\
9-13\end{array}$ & $\begin{array}{r}\mathrm{I}-0.576-0.105 \mathrm{pH} \\
\text { II }-1.142-0.011 \mathrm{pH} \\
\text { III }-0.680-0.089 \mathrm{pH} \\
\text { IV }-1.000-0.005 \mathrm{pH} \\
\mathrm{V}-0.805-0.079 \mathrm{pH}\end{array}$ & $\begin{array}{l}2.0-2.5 \\
2.2-2.7 \\
4.3-4.7 \\
4.8 \\
8.9^{d}\end{array}$ \\
\hline 2-Amino- & $\begin{array}{l}2-3 \\
4-7 \\
4-7 \\
7-9\end{array}$ & $\begin{array}{r}\mathrm{I}-0.685-0.049 \mathrm{pH} \\
\mathrm{I}-0.425-0.121 \mathrm{pH} \\
\text { II }-\mathbf{1} .360-0.004 \mathrm{pH} \\
\text { III }-0.680-0.090 \mathrm{pH}\end{array}$ & $\begin{array}{l}2.0 \\
2.1-2.4 \\
2.0-2.4 \\
4.0-4.3\end{array}$ \\
\hline 2-Amino-4-methyl- & $\begin{array}{l}2-4 \\
4-7 \\
5-7 \\
7-9\end{array}$ & $\begin{array}{r}\mathrm{I}-0.770-0.063 \mathrm{pH} \\
\mathrm{I}-0.550-0.113 \mathrm{pH} \\
\text { II }-1.424-0.008 \mathrm{pH} \\
\text { III }-0.745-0.094 \mathrm{pH}\end{array}$ & $\begin{array}{l}2.0 \\
2.1 \\
2.0 \\
4.0\end{array}$ \\
\hline 2-Hydroxy- & $2-8$ & $-0.530-0.078 \mathrm{pH}$ & 2.1 \\
\hline 4-Amino-2-hydroxy- (cytosine) & $\begin{array}{c}5.5 \\
4-6 \\
5\end{array}$ & $-1.125-0.075 \mathrm{pH}$ & $\begin{array}{l}4.9 \\
6.4\end{array}$ \\
\hline 4-Amino-6-hydroxy- & $\begin{array}{l}1.2 \\
6.8\end{array}$ & $\begin{array}{l}-1.18 \\
-1.62\end{array}$ & \\
\hline 4-Amino-2, 6-dimethyl & $\begin{array}{l}2-8 \\
2-5\end{array}$ & $-1.130-0.073 \mathrm{pH}$ & 6.8 \\
\hline 4-Amino-2, 5-dimethyl & $3-6$ & $-1.11-0.076 \mathrm{pH}$ & 4.8 \\
\hline 4-Hydroxy- & $\begin{array}{l}1.2 \\
6.8\end{array}$ & $\begin{array}{l}-1.16 \\
-1.60\end{array}$ & \\
\hline 2, 4-Diamino- & $\begin{array}{l}1.2 \\
6.8\end{array}$ & $\begin{array}{l}-1.16 \\
-1.52\end{array}$ & \\
\hline 4,$5 ; 6$-Triamino- & $\begin{array}{l}1.2 \\
6.8 \\
\end{array}$ & $\begin{array}{l}-1.17 \\
-1.57 \\
\end{array}$ & \\
\hline 1, 4-0-Dimethyl- (thymine) & $\begin{array}{l}1.2 \\
6.8 \\
\end{array}$ & $\begin{array}{l}-1.18 \\
-1.62 \\
\end{array}$ & \\
\hline Purine & $\begin{array}{l}2-6 \\
2-6\end{array}$ & $\begin{array}{r}\mathrm{I}-0.697-0.083 \mathrm{pH} \\
\text { II }-0.902-0.080 \mathrm{pH}\end{array}$ & $\begin{array}{l}3.8 \\
6.3 \\
\end{array}$ \\
\hline 6-Amino- (adenine) & $\begin{array}{l}1-3 \\
4-6 \\
2-6\end{array}$ & $\begin{array}{c}\mathrm{e} \\
\mathrm{e} \\
-0.975-0.090 \mathrm{pH}\end{array}$ & $\begin{array}{r}10.2 \\
10.2 \\
5.6\end{array}$ \\
\hline 6-Hydroxy- (hypoxanthine) & 5.7 & -1.61 & 2.75 \\
\hline
\end{tabular}

a Data selected from TABLES 2 and 3 of Reference 1, where references to the original sources are given.

b Roman numbers indicate successive polarographic waves; potentials are vs. S.C.E.

- Diffusion current constant, $\mathrm{I}=i_{1} / \mathrm{Cm}^{2 / 3} t^{1 / 6}$; each electron transferred per molecule reduced or oxidized contributes a value of about 2 . The values for purine and adenine are slightly high due to the presence of some concomitant hydrogen ion reduction (cf. References 4 and 22).

d At pH 13, I = 6 .

- Dependence of $\mathrm{E}_{1 / 2}$ on $\mathrm{pH}$ is similar to that given for $\mathrm{pH}$ range of 2-6, which is for McIlvaine buffers; these two sets of data are for chloride and acetate buffers, respectively. 
TABLE 2

Voltammetric Oxidation of Selected Purines at the Stationary Graphite Electrode ${ }^{a}$

\begin{tabular}{|c|c|c|c|}
\hline Compound & $\mathrm{pH}$ & $\begin{array}{c}\mathrm{E}_{\mathrm{p} / 2} \\
\mathrm{v} .\end{array}$ & $\begin{array}{c}\text { Ratiob }^{\mathrm{b}} \\
i_{\mathrm{p}} / \mathrm{C} \\
\mu \mathrm{a} / \mathrm{m} M\end{array}$ \\
\hline Purine & & (no wave) & \\
\hline 6-Amino-(adenine) & $\begin{array}{l}2.3^{-5.7} \\
5.5\end{array}$ & 1.03 to 1.07 & $\begin{array}{l}73^{\mathrm{c}} \\
48^{\mathrm{d}}\end{array}$ \\
\hline 2-Amino-6-hydroxy-(guanine) & $2 \mathrm{M} \mathrm{H}_{2} \mathrm{SO}_{4}$ & 1.02 & 50 \\
\hline 6-Amino-2-hydroxy- (isoguanine) & $2 \mathrm{M} \mathrm{H}_{2} \mathrm{SO}_{4}$ & 1.05 & 58 \\
\hline 6-Hydroxy- (hypoxanthine) & $2.3-5.7$ & 1.25 to 1.04 & 62 \\
\hline 2, 6-Dihydroxy-(xanthine) & $\begin{array}{c}2 \mathrm{M} \mathrm{H}_{2} \mathrm{SO}_{4} \\
3.7-5.7 \\
\end{array}$ & $\begin{array}{c}1.01 \\
0.84 \text { to } 0.71\end{array}$ & 49 \\
\hline $2,6,8$-Trihydroxy- (uric acid) & $\begin{array}{c}2 \mathrm{MH}_{2} \mathrm{SO}_{4} \\
3.7 \\
5.7\end{array}$ & $\begin{array}{l}0.62 \\
0.45 \\
0.33\end{array}$ & $\begin{array}{l}31 \\
34\end{array}$ \\
\hline
\end{tabular}

a Data taken from Reference 22, with the exceptions noted in footnotes $\mathrm{c}$ and $\mathrm{d}$. rod.

b Current values are those obtained at a 0.25 -inch diameter, wax-impregnated graphite

In the $\mathrm{pH}$ range of $2-5, \mathrm{E}_{\mathrm{p}}$ at a pyrolytic graphite electrode $=1.45-0.067 \mathrm{pH}$, with $i_{\mathrm{p}} / \mathrm{C}$ being 68 for a 0.25 -inch electrode (Reference 28 ).

d Obtained with a highly damped polarograph. (Reference 38 ).

proton from the solution or by electronic rearrangement that transfers the charge to another part of the molecule where it can be suitably handled.

Chemical reactions preceding, accompanying or following charge-transfer may-and often do-play significant roles in the overall process, as is subsequently indicated.

\section{Reduction of the Pyrimidine Ring}

The complex pattern observed for the reduction of pyrimidine at the D.M.E., in which five polarographic waves appear over the normal pH range (cf. TABLE 1), can be explained ${ }^{3}$ on the basis of the general electrode reaction mechanism described (FIgure 2): Wave I results from $1 e$ reduction of the 3,4 bond with the simultaneous acquisition of a proton to form a free radical, which may dimerize to $4,4^{\prime}$-bipyrimidine or be reduced at more negative potential in a further $1 e$ process (wave II) to 3,4 - dihydropyrimidine. Since wave I is strongly $\mathrm{pH}$-dependent and wave II is only slightly $\mathrm{pH}$ dependent, the two wages merge at about $\mathrm{pH} 5$ to form $\mathrm{pH}$-dependent $2 e$ wave III. Essentially $\mathrm{pH}$-independent wave IV, which appears at higher $\mathrm{pH}$, represents a $2 e$ reduction at more negative potential of the dihydropyrimidine to a tetrahydropyrimidine. The difference in $\mathrm{pH}$-dependency of waves III and IV result in their merging at about $\mathrm{pH} 9$ to form $\mathrm{pH}$-dependent $4 e$ wave $\mathrm{V}$.

\section{Reduction Paths for Purines and Pyrimidines}

Essentially, the reduction of pyrimidines, purines and their derivatives follows the course outlined for pyrimidine, i.e., the $3,4 \mathrm{~N}=\mathrm{C}$ bond in the 


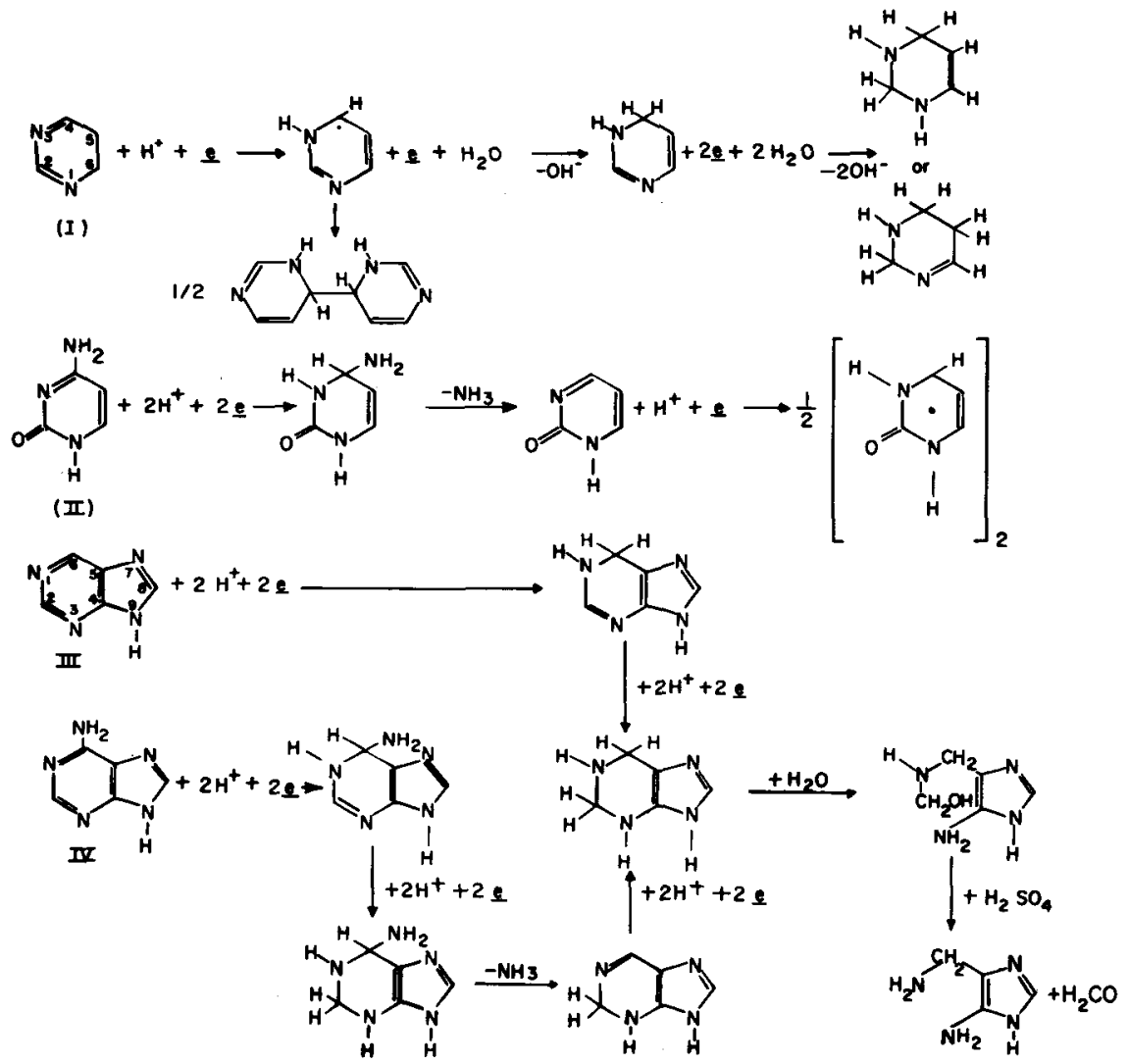

Figure 2. Interpretation of the electrochemical and chemical behavior observed on the polarographic reduction of pyrimidine (I), cytosine (II), purine (III), and adenine (IV). Protonation, dissociation and other acid-base and keto-enol equilibria, which may be involved, are not shown.

pyrimidine ring is usually the one most readily reduced, with possible modification resulting from structural and electron density alteration due to substituents: e.g., (a) fusing of consecutive electron-transfer steps or splitting of multiple-electron steps, (b) tautomeric shifts due to substituents having divalent sulfur or oxygen bonded to carbon with the resulting loss of reduction site, such as replacement of hydrogen by hydroxyl at the 2- or 4-position in pyrimidine results in removal of a double bond from the ring by ketonization, and (c) intramolecular chemical reactions accompanying electrode processes, such as deamination, which may generate electroactive species.

Thus, cytosine shows a single $3 e$ polarographic wave at a potential more negative than that of waves I-III of pyrimidine (cf. TABLE 1), which is due to three successive processes (FIgurE 2): (a) $2 e$ reduction of the $3,4 \mathrm{~N}=\mathrm{C}$ bond (this is a combination of the first two $1 e$ processes seen in pyrimidine), (b) rapid deamination of the product to 2-hydroxypyrimidine, and (c) $1 e$ reduction of the latter-similar to pyrimidine and the 2-aminopyrimidines-to 
a free radical, which dimerizes under the experimental conditions before it can be further reduced."

Purine exhibits two pH-dependent waves in acidic solution (TABLE 1). Wave I is due to $2 e$ reduction of the $1,6 \mathrm{~N}=\mathrm{C}$ double bond to 1,6 -dihydropurine; wave II is due to further $2 e$ reduction, probably to 1,2,3,6-tetrahydropurine, which hydrolyzes to a 4-aminoimidazole. ${ }^{4}$

The electrolytic reduction of adenine parallels that of purine and cytosine for an overall $6 e$ reduction: $2 e$ hydrogenation of the $1,6 \mathrm{~N}=\mathrm{C}$ bond at a potential more negative than that of both purine waves is immediately followed by $2 e$ reduction of the $2,3 \mathrm{C}=\mathrm{N}$ bond, slow deamination at the 6-position, further $2 e$ reduction of the regenerated $1,6 \mathrm{~N}=\mathrm{C}$ bond, and hydrolytic cleavage at the hydrogenated 2,3 position to give the same product as the overall $4 e$ purine reduction. ${ }^{4}$ At the D.M.E., the extent of deamination of the reduced adenine is negligible, resulting in a single pH-dependent $4 e$ wave.

\section{Reaction Sites}

Generalizations regarding oxidation and reduction sites in the bases are of obvious interest because of their biological importance. As indicated, the pyrimidine ring, for example, is involved in the electrochemical reduction of purines whereas the imidazole ring is untouched. On the other hand, the only two purines whose electrochemical oxidation has been thoroughly investigated (cf. subsequent discussion) are apparently attacked on oxidation at the double bond common to both rings.

\section{EfFect of Substituents on Ease of Reduction}

The effects of substituents, mainly amino and hydroxy groups, on the ease of electrochemical reduction of purines and pyrimidines are summarized in Reference 1 (largely on pages 151-153 and 160-161).

The effect of more elaborate substitution can be illustrated by the variation of $E_{1 / 2}$ values for the reduction of two interrelated series of compounds: a group of 6-substituted purines and one of adenine nucleosides and nucleotides. The 6-substituted purines were investigated ${ }^{5}$ because the naturally occurring purines are, with few exceptions, substituted in that position: e.g., the major purine constituents of nucleic acids, adenine and guanine, as well as minor constituents such as 2-methyladenine, 6-methylaminopurine and 6-dimethylaminopurine. The nucleoside-nucleotide group was investigated ${ }^{6}$ because, in spite of the fact that electrochemical reduction in nucleosides and nucleotides occurs primarily in the pyrimidine ring moiety, the sugar or sugar-phosphate group influences diffusion, adsorption, and electron density at reactive sites that generally manifests itself in potential shifts and possible alteration of the overall reaction path.

\section{6-Substituted Purines}

Only those 6-substituted purines (TABLE 3) were investigated, ${ }^{5}$ whose substituent is unlikely to remove by tautomeric shift the $1,6 \mathrm{~N}=\mathrm{C}$ bond, which is one of two possible reduction sites in purines. Since $\mathrm{E}_{1 / 2}$ of the one normal reduction wave of the 6-substituted purines is pH-dependent (a wave which may involve the reduced form of the purine appears at more negative potential 
in the case of a few compounds-6-methylpurine gives two ways); the potentials at $\mathrm{pH} 2.5$ and 4.0 in Mcllvaine buffer were selected for comparison. ${ }^{5}$

The diffusion current constant (TABLE 3) of the wave for all purines containing the 1, 6 and 2,3 double bonds in the pyrimidine ring is approximately the same as that of adenine, whose polarographic reduction involves a $4 e$ transfer; purine itself is reduced in two separate $2 e$ waves. In this respect, 6-methylpurine resembles the parental purine, while the 6-alkylamino-, 6-dialkylamino, and 6-methoxypurines resemble adenine (6-aminopurine). Similarly, the small change in the polarographic reduction of purine produced by introducing the 6-methyl group corresponds to small differences in total polar substituent constant, LEMO energies and other electronic indices, as subsequently discussed.

$\mathrm{E}_{1 / 2}$ of 6-substituted purines becomes more negative in the following order (substituent in 6-position indicated): (at $\mathrm{pH}$ 2.5) $\mathrm{H}, \mathrm{CH}_{3}, \mathrm{CH}_{3} \mathrm{O}, \mathrm{C}_{8} \mathrm{H}_{5} \mathrm{NH}$,

TABLE 3

Polarographic Reduction of 6-Substituted Purines at the DropPING MERCURY Electrode ${ }^{a}$

\begin{tabular}{|c|c|c|c|}
\hline Substituent & $\mathrm{pH}$ & $\begin{array}{c}\mathrm{E}_{1 / 2^{\mathrm{b}}} \\
\mathbf{v} .\end{array}$ & $I^{c}$ \\
\hline 6-Hydrogen & $\begin{array}{l}2-6 \\
2-6\end{array}$ & $\begin{array}{l}\text { I }-0.697-0.083 \mathrm{pH} \\
\text { II }-0.902-0.080 \mathrm{pH}\end{array}$ & $10.1^{\mathrm{d}}$ \\
\hline 6-Methyl & $\begin{array}{l}1-4 \\
4-6 \\
1-2 \\
2-6\end{array}$ & $\begin{array}{r}\mathrm{I}-0.825-0.069 \mathrm{pH} \\
\mathrm{I}-0.725-0.095 \mathrm{pH} \\
\text { II }-0.965-0.063 \mathrm{pH} \\
\text { II }-0.870-0.085 \mathrm{pH}\end{array}$ & $8.5^{\mathrm{d}}$ \\
\hline 6-Methoxy & $\begin{array}{l}1-2 \\
2-4 \\
4-6\end{array}$ & $\begin{array}{l}-0.945-0.069 \mathrm{pH} \\
-0.835-0.103 \mathrm{pH} \\
-0.620-0.157 \mathrm{pH}\end{array}$ & 8.5 \\
\hline 6-Amino & 1-6 & $-0.975-0.084 \mathrm{pH}$ & 9.8 \\
\hline 6-Methylamino & $1-6$ & $-0.995-0.081 \mathrm{pH}$ & 9.8 \\
\hline 6-n-Hexylamino & $\begin{array}{l}1-2.5 \\
2-5-4 \\
4-6\end{array}$ & $\begin{array}{l}-0.995-0.076 \mathrm{pH} \\
-1.100-0.049 \mathrm{pH} \\
-0.995-0.076 \mathrm{pH}\end{array}$ & 8.3 \\
\hline 6-Benzylamino & $\begin{array}{l}1-2 \\
2-4 \\
4-6\end{array}$ & $\begin{array}{l}-1.075-0.028 \mathrm{pH} \\
-1.000-0.065 \mathrm{pH} \\
-0.865-0.096 \mathrm{pH}\end{array}$ & 9.8 \\
\hline 6-Phenylamino & $\begin{array}{l}1-2 \\
2-5\end{array}$ & $\begin{array}{l}-0.885-0.097 \mathrm{pH} \\
-0.945-0.066 \mathrm{pH}\end{array}$ & 8.3 \\
\hline 6-Dimethylamino & $\begin{array}{l}1-2 \\
2-4\end{array}$ & $\begin{array}{l}-0.990-0.077 \mathrm{pH} \\
-1.025-0.067 \mathrm{pH}\end{array}$ & 8.9 \\
\hline 6-Amino-2-hydroxy & $\begin{array}{l}1-5 \\
5-7\end{array}$ & $\begin{array}{l}-0.995-0.071 \mathrm{pH} \\
-0.800-0.112 \mathrm{pH}\end{array}$ & 4.6 \\
\hline
\end{tabular}

- Data taken from References 1,5 and 6, generally for the pH region of 1 to 6 ; the wave, which can be measured for some compounds to $\mathrm{pH} 8$ or 9 , shows some dependence on buffer system used. Data given are for chloride and Mcllvaine buffers.

boman numbers indicate successive polarographic waves; potentials are vs. S.C.E.

- Diffusion current constant, $I=i_{1} / \mathrm{Cm}^{2 / 3} t^{1 / 6}$, calculated from data for Mclivaine buffer usually between $\mathrm{pH} 2.5$ and 4.5 , where $i_{1}$ varied least with $\mathrm{pH}$.

${ }^{d}$ Calculated from the total current of the two reduction waves. 
$\mathrm{C}_{6} \mathrm{H}_{5} \mathrm{CH}_{2} \mathrm{NH}$, isoguanine, $\mathrm{n}-\mathrm{C}_{6} \mathrm{H}_{13} \mathrm{NH},\left(\mathrm{CH}_{3}\right)_{2} \mathrm{~N}, \mathrm{NH}$, and $\mathrm{CH}_{3} \mathrm{NH}$, and (at $\mathrm{pH}$ 4.0) $\mathrm{H}, \quad \mathrm{CH}_{3,}, \mathrm{C}_{6} \mathrm{H}_{i} \mathrm{NH}, \mathrm{CH}_{3} \mathrm{O}, \mathrm{C}_{8} \mathrm{H}_{5} \mathrm{CH}_{2} \mathrm{NH}$, isoguanine, $\left(\mathrm{CH}_{3}\right)_{2} \mathrm{~N}$, $\mathrm{n}-\mathrm{C}_{6} \mathrm{H}_{13} \mathrm{NH}, \mathrm{CH}_{3} \mathrm{NH}$ and $\mathrm{NH}_{2}$. It is evident that reduction becomes more difficult as the basicity of the 6-substituent increases: for example, cf. order of increasing basicity of the corresponding amine. ${ }^{7}$

The mechanisms for the polarographic reduction of the 6-substituted purines do not differ essentially from those of the parental purine and adenine. This is apparent not only for the 6-alkylamino purines, whose $\mathrm{E}_{1 / 2}$ are linearly related to the polar substituent constants $(\sigma)$, but also for all 6-substituted purines examined, whose $\mathrm{E}_{1 / 2}$ are linearly related to total polar substituent constants $\left(\sigma_{p}\right)$ (FIGURE 3 ). The correlation of $\mathrm{E}_{1 / 2}$ with $\sigma$ and $\sigma_{p}$ indicates either that no mesomeric and steric effects due to the substituents are involved, or that they are transmitted by an inductive mechanism. ${ }^{8-10}$

\section{Correlation of $E_{1 / 2}$ with Electronic Indices}

The ease of polarographic reduction, as represented by $E_{1 / 2}$, can be compared with electron-acceptor properties as represented by the energy of the lowest empty molecular orbitals (LEMO) calculated by the Hückel LCAO molecular-orbital approximation method11 (FIGURE 4). Fairly linear relationships are obtained for purine, 6-methylpurine, adenine and 6-methoxypurine

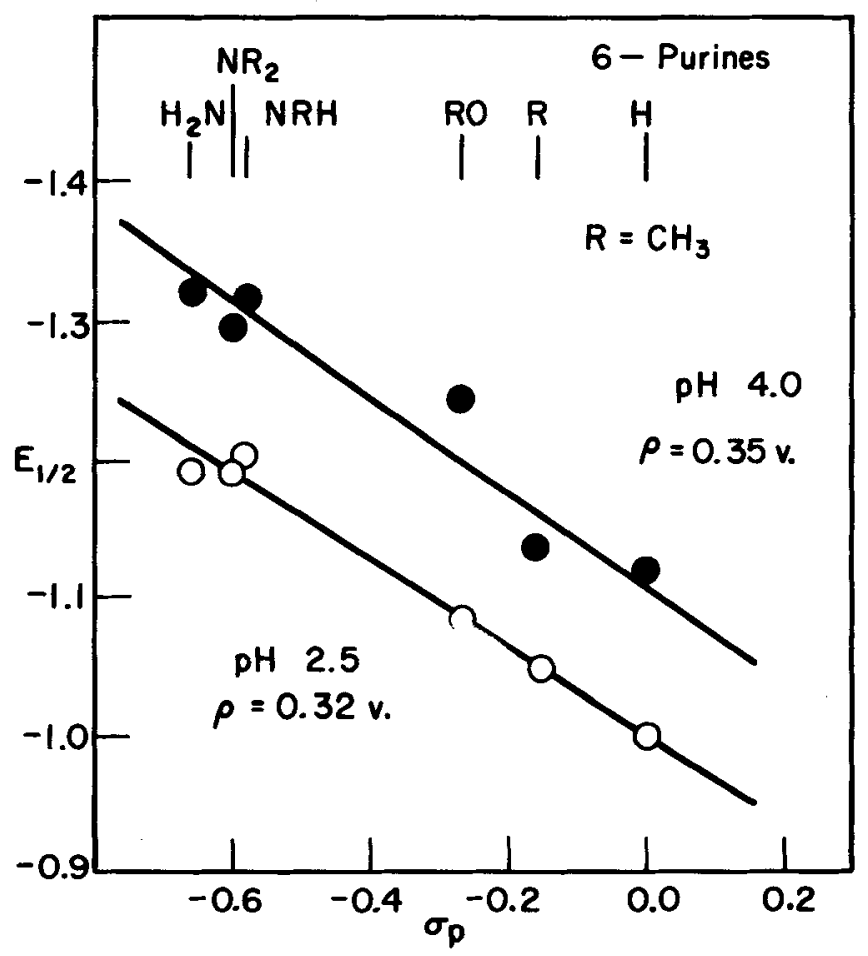

FIGURE 3. Variation of $E_{1 / 2}$ of the (first) reduction wave of 6-substituted purines with the total polar substituent constant, $\sigma_{\mathrm{p}}$. Data for purine and adenine from References 25 and 6, respectively; data for other compounds from Reference 5. 


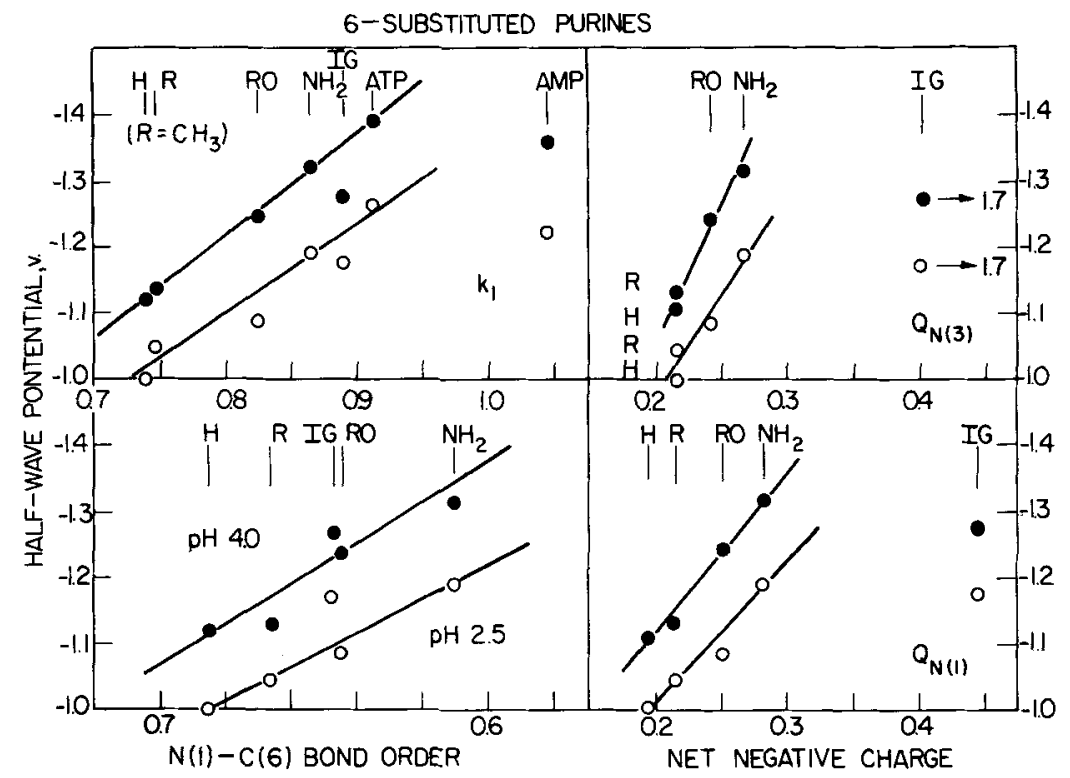

FIGURE 4. Variation of $E_{1 / 2}$ of 6 -substituted purines with LEMO energies $\left(k_{i}\right)$, $\mathrm{N}(1)-\mathrm{C}(6)$ bond order, and net negative charges on $\mathrm{N}(1)$ and $\mathrm{N}(3) . \mathrm{R}=\mathrm{CH}_{3}$; $\mathrm{IG}=$ isoguanine; AMP $=$ adenosine $5^{\prime}$-monophosphate; ATP $=$ adenosine 5 '-triphosphate. $\mathrm{E}_{1 / 2}$ data for purine from Reference 25, for ATP and AMP from Reference 6, and for other compounds from Reference 5; quantum chemical data from Reference 11. Solid circles represent values measured at $\mathrm{pH} 4.0$; open circles, at $\mathrm{pH}$ 2.5 .

(data calculated for the hypoxanthine lactim form were used for the latter); ATP fits the correlation, but AMP does not. Isoguanine does not fit this or any of the subsequent correlations discussed.

Substitution in the 6-position influences mostly the $\mathrm{N}(1)-\mathrm{C}(6)$ bond order and the electronic charge distribution on $\mathrm{N}(1)$ and $\mathrm{N}(3)$ which, in turn, largely determine the reducibility; $\mathbf{E}_{1 / 2}$ correlates with these (FIGURE 4), but not with the $\mathrm{C}(2)-\mathrm{N}(3)$ bond order and the charges on $\mathrm{C}(6)$ and $\mathrm{C}(2)$. These results are in accord with the previously suggested ${ }^{4}$ association of the initial purine and adenine reduction steps with the $1,6 \mathrm{~N}=\mathrm{C}$ bond, which, moreover, seems more accessible for reduction than the $2,3 \mathrm{C}=\mathrm{N}$ bond. For example, isoguanine (2-hydroxy-6-aminopurine) exhibits a well-defined wave, whereas hypoxanthine (6-hydroxypurine) only shows an ill-defined inflection on the background discharge, ${ }^{4}$ and guanine (2-amino-6-hydroxypurine) is polarographically reduced only at potentials more negative than the background discharge by a different mechanism than adenine and its other derivatives. ${ }^{4}, 12,13$

Since apparently only the protonated form of purine derivatives is polarographically reducible," correlation of $E_{1 / 3}$ with acidic dissociation constants ( $\mathrm{pK}$. values) may be expected. Adenine-and presumably other 6-substituted purines -is protonated first at $\mathrm{N}(1)$, i.e., at the most basic nitrogen. ${ }^{11,14,15}$ Although the electronic density on the ring nitrogen cannot be taken alone as a measure of its basicity, ${ }^{11}$ as a first approximation, the reducibility should be inversely proportional to the electronic density on $\mathrm{N}(1) ; \mathrm{E}_{1 / 2}$ does become more negative 
as the net negative charge on N(1) increases (FIGURE 4). Unfortunately, $\mathbf{p K}_{\mathbf{a}}$ values are not available for all of the compounds tested and some had to be estimated from inflections in the $i-\mathrm{pH}$ and $\mathrm{E}_{1 / 2}-\mathrm{pH}$ plots. Consequently, the correlations obtained are not too conclusive, although several 6-substituted derivatives do fit a straight line $\mathrm{E}_{1 / 2}-\mathrm{pK}_{\mathrm{a}}$ plot (FIGURE 5).

\section{Behavior of Isoguanine}

As noted, $E_{1 / 2}$ for the reduction of isoguanine deviates markediy from the linear correlations of $\mathrm{E}_{1 / 2}$ with net negative charge on $\mathrm{N}(1)$ and $\mathrm{N}(3)$, and with $\mathrm{pK}_{\mathrm{a}}$ shown by other 6-substituted purines. However, its $\mathrm{E}_{1 / 2}$ deviates only slightly from the linear plots of $E_{1 / 2}$ vs. LEMO energy $\left(k_{1}\right)$ and $N(1)-C(6)$ bond order. This behavior may be correlated - at least to some extent - with the reduction site and the effect of protonation on the latter.

The diffusion current constant of isoguanine is about one-half that of adenine and related compounds, which is consistent with a $2 e$ process based on only the 1, 6 double bond being reducible, since the 2,3 double bond is unavailable due to the stability of the keto form. The agreement of isoguanine $\mathrm{E}_{1 / 2}$ with LEMO energy and $\mathrm{N}(1)-\mathrm{C}(6)$ bond order may then be ascribed to the connection of the latter with the reduction site. Protonation of isoguanine does not seem to play a decisive role in its polarographic reduction, i.e., the inflection point in the $i$-pH curve is at least $5 \mathrm{pH}$ units higher than its $\mathrm{pK}_{\mathrm{a}}$ compared to 2 to 3 units for other 6-substituted purines. ${ }^{5}$ Even if apro-

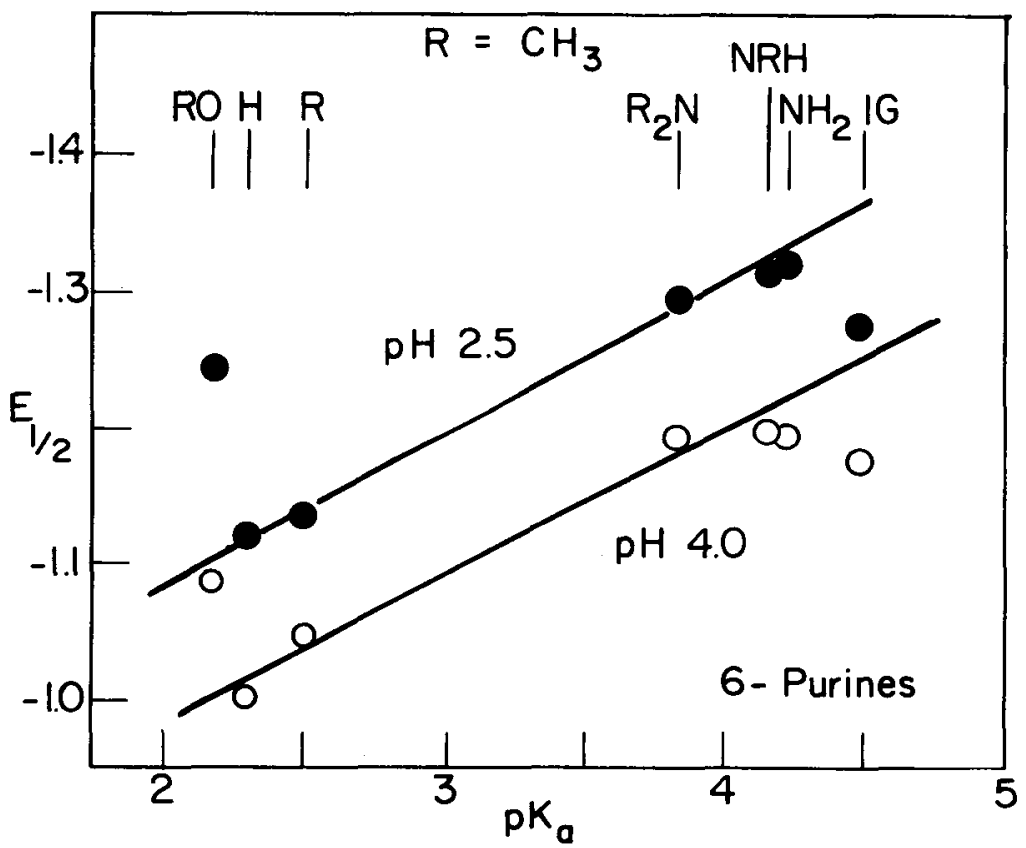

Figure 5. Variation of $E_{1 / 2}$ of 6-substituted purines with the acid dissociation constant $p K_{\mathrm{a}}$. $\mathrm{E}_{1 / 2}$ data for purine and adenine from References 25 and 6 , respectively; $\mathbf{E}_{1 / \mathbf{a}}$ data for other compounds from Reference $5 ; \mathbf{p K}_{\mathrm{a}}$ values from Reference 7 . IG $=$ isoguanine. 
tonated species were involved in the reduction, the most probable protonation site based on comparison of $\mathrm{N}$-charges ${ }^{11}$ is $\mathrm{N}(7)$, which is not at the reduction site.

\section{Adenine Nucleosides and Nucleotides}

The polarographic behavior of adenine does not change drastically on attachment of a sugar or sugar-phosphate moiety; the current-controlling factors and the reduction mechanisms are common, in principle, for the whole series. ${ }^{*}$ Each compound (TABLE 4) generally shows one well-defined cathodic polarographic wave, which may be distorted in the case of AMP, dAMP and ATP by the appearance of a second wave at more negative potential, probably due to the catalytic reduction of hydrogen. The overall behavior pattern is fundamentally similar to that observed for adenine itself.4, 6

The wave is relatively constant in height for all compounds up to $\mathrm{pH} 4$ or 5, when it begins to decrease sharply and disappears by $\mathrm{pH} 6$ or 7 ; the apparent diffusion current constants (TABLE 4) for the wave agree within $10 \%$ with that of the parent adenine, indicating a $4 e$ process under polarographic conditions. ${ }^{6} \mathrm{E}_{1 / 2}$ becomes more negative with increasing $\mathrm{pH} ; \mathrm{d}\left(\mathrm{E}_{1 / 2}\right) /$ $\mathrm{d}(\mathrm{pH})$ varies from 0.04 to 0.08 volt per $\mathrm{pH}$ unit, compared to a theoretical value of 0.06 for a reduction involving the same number of electrons and protons in the potential-determining step of the electrode process.

The correlation of $\mathrm{E}_{1 / 2}$ with structure in the series of a purine or pyrimidine base with its nucleosides and nucleotides is more complex than in the case of simple derivatives, e.g., purines or pyrimidines substituted only with alkyl, alkylamino or amino groups for which $E_{1 / 2}$ has been, on the whole, well correlated with electronic density at the reduction site and $\mathrm{pK}_{\mathrm{a}}{ }^{5}$ This is

TABLE 4

Polarographic Reduction of adenine Nucleosides and Nucleotides at the Dropping Mercury Electrode ${ }^{\mathrm{a}}$

\begin{tabular}{|c|c|c|c|}
\hline Compound ${ }^{b}$ & $\mathrm{pH}$ & $\begin{array}{c}\mathrm{E}_{1 / 2} \\
\mathrm{v} .\end{array}$ & $\mathbf{I}^{\mathbf{c}}$ \\
\hline Adenine & $1-6.5$ & $-0.975-0.084 \mathrm{pH}$ & 9.7 \\
\hline Adenosine & $\begin{array}{l}2-4.5 \\
4.5-6 \\
\end{array}$ & $\begin{array}{l}-0.040-0.070 \mathrm{pH} \\
-1.180-0.041 \mathrm{pH} \\
\end{array}$ & 10.2 \\
\hline Deoxyadenosine & $\begin{array}{l}2.5-4.6 \\
4.6-6.5\end{array}$ & $\begin{array}{l}-1.060-0.069 \mathrm{pH} \\
-1.205-0.037 \mathrm{pH}\end{array}$ & 10.8 \\
\hline AMP & $\begin{array}{l}1-4 \\
4-5.5\end{array}$ & $\begin{array}{l}-1.015-0.083 \mathrm{pH} \\
-1.115-0.060 \mathrm{pH}\end{array}$ & 10.2 \\
\hline dAMP & $2-6.5$ & $-0.985-0.080 \mathrm{pH}$ & 10.8 \\
\hline ATP & $\begin{array}{l}2.5-4.5 \\
4.5-5.5\end{array}$ & $\begin{array}{l}-1.035-0.083 \mathrm{pH} \\
-1.175-0.052 \mathrm{pH}\end{array}$ & d \\
\hline
\end{tabular}

a Data taken from Reference 6.

b AMP: adenylic acid or adenosine 5'-monophosphate; dAMP: deoxyadenylic acid or deoxyadenosine $5^{\prime}$-monophosphate; ATP: adenosine 5 '-triphosphate.

c Diffusion current constant, $\mathrm{I}=i_{1} / \mathrm{Cm}^{2 / 3} t^{1 / 6}$, calculated from data for McIlvaine buffer between $\mathrm{pH} 2.5$ and 4.5 , where $i_{1}$ varies least with $\mathrm{pH}$ or reaches a maximum.

$d$ The wave height could not be measured meaningfully, due to merging with a subsequent catalytic wave. 
probably due in large part, if not entirely, to the more complex structure in the nucleosides and nucleotides, resulting in increased adsorption and greater possibility for intramolecular association.

Attachment of a sugar or sugar-phosphate moiety to the adenine nucleus generally decreases the ease of reducibility of the parent compound; the exact order of reducibility is slightly $\mathrm{pH}$ and concentration-dependent, e.g., $\mathrm{E}_{1 / 2}$ in $\mathrm{pH} 3.7 \mathrm{McIl}$ vaine buffer becomes more negative in the order: dAMP $\leq$ adenine $<$ adenosine $<$ deoxyadenosine $<$ AMP $<$ ATP. The alternating current polarographic behavior of these compounds suggests a generally parallel order of increasing adsorbability; the general pattern is thus consistent with a frequently observed inhibition of the electrolytic process due to strong adsorption of the depolarizer with a consequent negative shift of the wave. ${ }^{16}$

Adsorbability, however, is obviously not the only factor influencing the reducibility in the adenine series. The electron-withdrawing effect of the ribose ring in nucleosides ${ }^{17}, 18$ should promote nucleophilic attack on the heterocyclic ring, i.e., should increase its ease of reducibility. This prediction seems to be fulfilled in the case of the cytosine series, in which the reducibility increases in the order: base $<$ nucleoside $<$ nucleotide. ${ }^{19,} 20$ In the adenine series, the distance between the sugar ring and the reduction sites in the pyrimidine ring is long enough to weaken electron withdrawal from the sites; other factors may also contribute to the decreased reducibility of nucleosides and nucleotides. ${ }^{6}$ The fact that ATP is the most difficultly reducible of the group is due partially to the repulsion of the negatively charged phosphate groups from the similarly charged D.M.E. surface and partially to the remarkable stability of energy-rich ATP in water medium. ${ }^{11}$ ATP assumes a more condensed structure than the other compounds, in which two terminal phosphate groups approach the relatively positive amino group and $\mathbf{N}(7)$, which are thus surrounded by a protective cloud of negatively charged phosphate groups.

Adenine and ATP fit the straight-line relation between $E_{1 / 2}$ and $k_{1}$ (energy of LEMO) obtained for purine and some of its 6-substituted derivatives, whereas AMP deviates significantly (FIGURE 4). $E_{1 / 2}$ values for the cytosine series (bases, nucleosides and nucleotides) are more negative than those for the corresponding adenine derivatives, whereas the LEMO calculations predict the opposite.

The presence of the protonated species (with the proton most probably being on the $\mathrm{N}(1)$ ), as indicated by $\mathrm{NMR}^{17}$ and $\mathrm{x}$-ray crystallography, ${ }^{21}$ as the only polarographically reducible form is supported by a number of polarographic observations. ${ }^{6}$ Since, to a first approximation, $\mathrm{pK}_{\mathrm{a}}$ values of organic compounds are proportional to the electron density at the protonation site, ease of reducibility should decrease with increasing $\mathrm{pK}_{\mathrm{a}}$ in the adenine series in which the protonation site, $\mathrm{N}(1)$, is also the reduction site. However, such agreement is observed only for adenosine, deoxyadenosine, AMP and ATP; adenine and dAMP strongly deviate in being more easily reduced than expected for an inverse $\mathrm{pK}_{\mathrm{t}}-\mathrm{E}_{1 / 2}$ correlation.

\section{Oxidation of Purines and Pyrimidines}

None of the simpler pyrimidines investigated, e.g., those with only one or two amino or hydroxy substituents, give an oxidation wave at graphite or mercury electrodes ${ }^{1,22}$; a polysubstituted pyrimidine such as dialuric acid does. ${ }^{23}$ It was concluded ${ }^{24}$ from a study of the polarographic oxidation of 
some 4, 5-dihydroxypyrimidines at a micro platinum anode in acetic acid solution that pyrimidines without a $5-\mathrm{OH}$ group could not be oxidized, and that pyrimidines with an enediol structure (HOC:COH) could be oxidized polarographically to $\mathrm{CO} . \mathrm{CO}$.

All purines investigated,1, 22, 25, 26, 27, 28 with the exception of purine itself, give an anodic wave at the graphite electrode (TABLE 2); the compounds, in order of decreasing ease of oxidation (increasingly more positive half-peak potential at constant $\mathrm{pH}$ ), are: uric acid, xanthine, guanine, isoguanine, adenine, hypoxanthine and purine (the last, as mentioned, is not oxidized within the available potential range). Potentials become more positive (oxidation, more difficult) with decreasing $\mathrm{pH}$; the ease of oxidation increases with the number of hydroxy groups (TABLE 2). Investigation of the electrolytic oxidation of purines prior to the work of the present author and his collaborators is apparently limited to a single study, ${ }^{29}$ the significance of which is lessened by the probable occurrence of concommitant chemical oxidation due to oxygen evolution resulting from lack of control of the electrode potential. The author and his collaborators have thus far investigated in detail the oxidation of uric $\operatorname{acid}^{27}$ and of adenine ${ }^{28}$ at controlled electrode potential; in acid solution, uric acid gives a fundamental $2 e$ anodic polarographic wave at graphite, and adenine gives a $6 e$ anodic wave.

The chemical oxidation of uric acid, depending on experimental conditions, produces as the principal product either allantoin or alloxan, but not both. The electrochemical oxidation of uric acid involves a $2 e$ oxidation to a primary short-lived dicarbonium ion, which undergoes simultaneous transformations including hydrolysis, leading to an allantoin precursor, alloxan, carbon dioxide and urea (there is some further oxidation of the ion to parabanic acid). ${ }^{27}$ The plausibility of postulating an intermediate which can undergo transformation to either allantoin or alloxan suggests that the oxidation of uric acid by any method produces a common intermediate whose subsequent transformations - and consequently the ultimate products obtained-are determined by experimental conditions. An analogous reaction path has been postulated $^{30}$ to explain the results for the enzymatic uricase oxidation of uric acid, reflecting a parellelism between the two types of oxidation.

The electrochemical oxidation of adenine appears, initially, to follow the same path as the enzymatic oxidation with xanthine oxidase, but further oxidation and fragmentation of the purine ring occur ${ }^{28}$ : i.e., adenine is oxidized in a process involving addition of oxygen to the two available carbon sites, $C(2)$ and $C(8)$, and removal of a total of 6 electrons per molecule to a dicarbonium ion intermediate, which is similar to that produced on uric acid oxidation except for having an $\mathrm{NH}_{2}$ group instead of an $\mathrm{OH}$ group on the $\mathrm{C}(6)$ with the resulting presence of the $1,6 \mathrm{~N}=\mathrm{C}$ bond. The dicarbonium ion is unstable and undergoes further reactions involving electrochemical oxidation and reduction as well as hydrolysis to yield parabanic, oxaluric and 4aminopurpuric acids, allantoin, urea, carbon dioxide and ammonia. The fact that oxidation of adenine continues to the dicarbonium ion stage is due to the fact that 2-hydroxy - and 2,8-dihydroxyadenine are probably more easily oxidized electrolytically than adenine itself and are consequently unstable in respect to oxidation at the potential at which adenine is oxidized (cf. TABLE 2).

\section{Correlations Involving Potentials}

Among the reasons for investigating in detail the electrochemical behaviorgenerally, the polarography-of biologically important compounds such as 
purines, pyrimidines and their derivatives, are the possible correlation between (a) the mechanistic paths involved and the characteristic potentials associated with them, and (b) chemical, biological and clinical activity.

Correlation of relatively readily measured polarographic $\mathrm{E}_{1 / 2}$ values with numerical structural and reactivity characteristics is usually based on the postulation that the characteristic $E_{1 / t}$ of a compound is a function of electron density and other factors that are also relatively simply related to some biological, physical or chemical property. The frequently resulting linear relationship between $E_{1 / 2}$ for a series of more or less closely related compounds and a suitably selected mathematical function of the values of the given property for that series of compounds permits: (a) prediction of the magnitude of the property of a compound from its readily measured $E_{1 / 2}$, and (b) the rapid comparative evaluation of a property based on comparison of $E_{1 / 2}$ values.

A large variety of experimental and theoretically calculated properties and phenomena have been compared to polarographically determined potentials, e.g., photoionization potentials, degree of carcinogenesis, wavelengths of spectrophotometric absorption maxima and antioxidant ability. The most extensively used correlations have involved various forms of the Hammett sigmarho equation based on polar substituent quantities and the Taft modification (cf. reviews by Perrin ${ }^{31}$ and Zuman ${ }^{10,32}$ ); perhaps the most significant have involved quantum-mechanically calculated parameters ( $\mathrm{cf}$. reviews by Pullman and Pullman ${ }^{11}$ and Zahradnik and Parkanyi ${ }^{33}$ ).

Correlations of molecular orbital (MO) calculations with polarographic data generally involve the quantum-mechnically calculated energies for adding an electron to the lowest empty MO (LEMO) or removing one from the highest occupied MO (HOMO). A priori, the optimum approach would seem to involve the use of electrochemical data based on initial $1 e$ processes, since the MO data apply to such processes.

Since MO calculations have been correlated with various types of chemical and biochemical activity for a variety of molecules, a successful correlation with polarographic data will facilitate correlation of biochemical activity with polarographic data. The need for methods which experimentally measure the electron affinities or related properties of biological compounds has been emphasized. ${ }^{11}$ The value of reliable polarographic potentials as tests of theoretical approaches to the electronic properties of biological molecules is typified by a recent paper ${ }^{15}$ in which the calculated ionization potentials (electron-donor properties) and electron affinities (electron-acceptor properties) of the four nucleic acid bases (guanine, adenine, cytosine and uracil) were evaluated by comparing them with oxidation potentials determined at the graphite electrode and reduction potentials determined at the D.M.E. The correlation of $\mathrm{E}_{1 / 2}$ data for the 6-substituted purines has been discussed.

Three frequently overlooked but important factors must be emphasized. The reliability of correlations of the type discussed depends on the calculations and measurements having been made on identical molecular species. It is for this reason, among others, that the details of the electrochemical redox reaction pathway-including the sites at which electron transfer occurs and their exact chemical nature-need to be elucidated, since only on this basis is it possible to assure that theoretical and experimental data are being compared for the same molecular species.

A second factor is the influence of the degree of reversibility of the electron-transfer process upon observed potential; whereas the potential ob- 
served for a completely reversible electrode process is directly relatable to the standard free energy of the process, that observed for one which is not so reversible contains a component due to the necessary energy of activation as well as components due to adsorption and other accompanying phenomena (cf. Reference 34).

Finally, account must be taken of the solvation energy contribution to the $\mathrm{E}_{1 / 2 \text {. }}$ Theoretical calculations are frequently based on an idealized gas-phase molecule. Consequently, there has been the implicit assumption in many past correlations that the solvation energy term is constant, or varies in a regular fashion for the series of compounds studied. The latter assumption has to be examined for the purines, pyrimidines, and their nucleosides and nucleotides because of the variation, for example, in the nature, number and strength of the hydrogen-bonding donor and acceptor groups in the different compounds and in their reduction and oxidation products.

\section{AdSORPTION ON AND REVERSIBILITY at ElECTRODES}

As has been indicated, it is important to evaluate the roles of adsorption of reactants and products on the electrode, of reversibility of the electrontransfer step, and of accompanying chemical reactions, since these could seriously alter the potential that would be observed in their absence and would be the potential desired for comparison with calculated energies for the electron-transfer step.

Alternating current polarographic data strongly support the assumption that all of the purine-based compounds studied are adsorbed on mercury. ${ }^{5}, 6,35$ The fact that only cytosine of the four pyrimidines examined (pyrimidine, cytosine, and 2-amino- and 2-hydroxypyrimidine) showed any evidence for adsorption at mercury ${ }^{35}$ suggests that the site of adsorption of purines lies in the imidazole ring, specifically-since position 9 is occupied in the adenosines-at either position 7 or 8 . Since position 7 contains a heterocyclic nitrogen, adsorption is more likely to involve this position. Adsorption may also involve pi-bonding to the aromatic ring.

Significantly, Vetterl,36, 37 who examined the effect of various purines and pyrimidines on the differential capacity at the D.M.E., found evidence for strong intermolecular interaction of adsorbed molecules only with the usual DNA and RNA components such as adenine, guanine, thymine, cytosine and uracil, but not with anomalous DNA components such as 5-methyl- and 5-hydroxymethylcytosine-at least not at the low concentrations for which effects were seen for the former compounds.

The data for adsorption on graphite electrodes are fragmentary; however, cyclic voltammetry indicates that purine and adenine are probably adsorbed on graphite.

\section{ACKNOWLEDGMENTS}

The author thanks the National Science Foundation, which helped support the work described, as well as his past and present collaborators on the polarographic behavior of purines and pyrimidines: Glenn Dryhurst, Borivoj Janik, James E. O'Reilly, Conrad O. Schmakel, David L. Smith and William A. Struck. 


\section{REFERENCES}

1. Elving, P. J., W. A. Struck \& D. L. Smith. 1965. Mises Point Chim. Anal. Org. Pharm. Bromatol. 14: 141.

2. Elving, P. J., \& B. Pullman. 1961. In Advances in Chemical Physics. I. Prigogine, Ed. 3: 1-31. Interscience Publishers. New York, N. Y.

3. Smith, D. L. \& P. J. Elving. 1962. J. Amer. Chem. Soc. 84: 2741.

4. Smith, D. L. \& P. J. Elving. 1962. J. Amer. Chem. Soc. 84: 1412.

5. JANIK, B. \& P. J. ElvING. To be published.

6. JANIK, B. \& P. J. ELVING. To be published.

7. Perrin, D. C. 1965. Dissociation Constants of Organic Bases in Aqueous Solutions. Butterworth. London, England.

8. Zuman, P. 1960. Ric. Sci., Suppl. Contrib. Teor. Sper. Polarogr. 5: 229.

9. Zuman, P. 1966. In Modern Aspects in Polarography. T. Kambara, Ed.: 102-16. Plenum Press. New York, N. Y.

10. Zuman, P. 1967. Substituent Effects in Organic Polarography. Plenum Press. New York, N. Y.

11. Pullman, B. \& A. Pullman. 1963. Quantum Biochemistry. John Wiley \& Sons. New York, N. Y.

12. JANIK, B. \& E. PaleceK. 1966. Z. Naturforsch. 21 b: 1117.

13. JANIK, B. \& E. PALeceK. 1966. Abhandl. Deut. Akad. Berlin, K1. Med.: 513.

14. DekKer, C. A. 1960. Ann: Rev. Biochem. 29: 463.

15. Berthod, H., C. Giessner-Prettre \& A. Pullman. 1966. Theoret. Chim. Acta 5: 53.

16. VolKe, J. 1965. Talanta 12: 1081.

17. JARDETZKY, C. D. \& D. JARDETZKY. 1960. J. Amer. Chem. Soc. 82: 222.

18. Broom, A. D., M. P. Schweizer \& P. O. P. Ts'o. 1967. J. Amer. Chem. Soc. 89: 3612 .

19. JanIK, B. \& E. Palecek. 1964. Arch. Biochem. Biophys. 105: 225.

20. Palecex, E. \& B. Janik. 1962. Arch. Biochem. Biophys. 98: 527.

21. COCHRAN, W. 1951. Acta Crystallogr. 4: 81.

22. SMith, D. L. \& P. J. Elving. 1962. Anal. Chem. 34: 930.

23. Struck, W. A. \& P. J. Elving. 1964. J. Amer. Chem. Soc. 86: 1229.

24. Chiang, K. C. P. Chang. 1958, 1959. Hua Hsueh Hsueh Pao. 24: 300; Chem. Abstr. 53: 20080.

25. SMITH, D. L. 1962. Ph.D. Thesis. University of Michigan. Ann Arbor, Mich.

26. Struck, W. A. 1963. Ph.D. Thesis. University of Michigan. Ann Arbor, Mich.

27. Struck, W. A. \& P. J. Elving. 1965. Biochem. 4: 1343.

28. Dryhurst, G. \& P. J. Elving. 1968. J. Electrochem. Soc. 115: 1014.

29. Fichter, F. \& W. KerN. 1926. Helv. Chim. Acta 9: 429.

30. Soberon, G. \& P. P. Cohen. 1963. Arch. Biochem. Biophys. 103: 331.

31. Perrin, C. L. 1966. In Progress in Physical Organic Chemistry. S. G. Cohen, Ed. 3: 165-316. Interscience Publishers. New York, N. Y.

32. Zuman, P. 1964. Organic Polarographic Analysis. Pergamon Press. London, England.

33. Zahradnit, R. \& C. Parkanyi. 1965. Talanta 12: 1289.

34. Elving, P. J. 1963. Pure Appl. Chem. 7: 423.

35. Dryhurst, G. \& P. J. Elving. Tallanta. To be published.

36. VetTerL, V. 1966. Abhandl. Deut. Akad. Wiss. Berlin, K1. Med.: 493.

37. Vetterl, V. 1966. Collection Czech. Chem. Commun. 31: 2105.

38. Elving, P. J. \& D. L. SMith. 1960 Anal. Chem. 32: 1849. 